\title{
ANALYSIS OF RELATIONSHIP BETWEEN MARKET VALUE OF PROPERTY AND ITS DISTANCE FROM CENTER OF CAPITAL
}

\author{
Eduard Hromada \\ Czech Technical University in Prague, Czech Republic \\ eduard.hromada@fsv.cvut.cz
}

\begin{abstract}
The paper deals with a study of the relationship between the market value of a property, location of the property, and its distance from the centre of the capital. Buyers are willing to pay a higher purchase price for a property, when it is located near the centre of the capital city, but the extent of this willingness has not yet been fully investigated. The author of the paper has developed software, which is able to automatically collect all offers for sale and lease of properties in the Czech Republic that have been published on the Internet. Data are collected and analysed from all cities in the Czech Republic regularly within a period of one month. The software has been running continuously since 2007. The following variables are examined: distance from the city centre in kilometres, availability of the city centre using urban public transport measured in minutes spent in the means of transport, and accessibility of the city centre using a passenger car measured in minutes spent in the means of transport. All significant towns and villages close to the capital city of Prague, where people commute to Prague, and where there are enough price offers to ensure relevant statistical evaluation, are analysed for the purpose of the paper results. Similarly, the market prices for renting a flat in the same locations are also evaluated in the paper. The outcomes of both analyses are compared.
\end{abstract}

Keywords: market value, real estate, regression analysis, correlation coefficient, rural development.

\section{Introduction}

Market value is determined by many socioeconomic factors, such as: location, type of property, technical state of property, age, type of ownership, dwelling size, bearing of windows in relation to points of the compass, character of neighbourhood and social structure of inhabitants, purchasing power, accessibility of mortgage, macroeconomics, unemployment rates, risk level, and many other factors. It shows that there is a considerable relationship between the property's market value and its distance from a regional centre or the capital. So far, this relationship has not been examined closely.

Article [1] deals with a similar issue. It explores the depreciation of the property's market value for each extra minute of commuting to the center of the capital. The article analyses neighborhoods of Prague. Article [2] studies a complementary topic - it deals with values of property for commerce and their relation to accessibility of motorways or railways. The article explores the impact of both positive externalities (stations, motorway exits) and negative externalities (crossroads, railway crossings) of infrastructure. Article [3] researches the impact of a new commuter line of mass transportation in Singapore on market prices of residential property. It deals with the difference of the market value of housing before and after opening the new commuter line. The authors use regression analysis to identify differences of the impact on residential property, as it is related to the distance of the property from the line and its stations. The author of this article has been researching long-term property market tendencies in the Czech Republic. Article [4] defines basic real estate tendencies in the Czech Republic. Study [5] focuses on creation of a database, which contains hedonic characteristics and coefficients, which influence the real estate market value. The database determines the value of any given property based on comparison with a similar property, which had been sold shortly before. The paper [6] presents a hedonic model of land prices. It assesses the usability of land prices as an indicator of the efficiency, by which different delineations of a given city capture the influence area of that city.

\section{Materials and methods}

The author has developed software, which is capable of amassing all price offers of property on sale or for rent in the Czech Republic, which are published on the Internet. Data are collected and analyzed about all cities in the Czech Republic within a regular period of one month. The software has been operating continually since 2007. For a better idea of the amount of data, which can thus be collected, let us state that the database includes over 750,000 new entries from the second half of the year 2017. The data include all price offers on both the sale and rent of residential houses, flats, parcels, and all commercial property. The data which had been acquired allow us to analyze and 
describe behavior, and identify changes and trends in the current real estate market. Such analyses are based on a large collection of trustworthy data.

This article is based on the regression analysis, which explores the relationship between the market price for $1 \mathrm{~m}^{2}$ of floor space and the distance and accessibility of the centre of the capital. The analysis explores the following variables:

- distance from the centre of the capital, in $\mathrm{km}$,

- accessibility of the centre of the capital using public transportation, measured in minutes spent in given means of transportation,

- accessibility of the centre of the capital using a passenger car, measured in minutes spent in the passenger car.

For the purpose of this article, all relevant cities and municipalities in the vicinity of the capital have been analysed, with respect to two factors - whether inhabitants commute to Prague for work, and whether there is sufficient amount of price offers to enable statistically relevant processing. Similarly, price offers of flats for rent have been analysed.

The author has established the underground station Mustek (St. Wenceslas Square) as the central business district (CBD) for the purposes of this study. Distance and commute times were acquired via https://mapy.cz/. Distances as stated represent the real distance on the roads from place A to place B. It is not airline distance between points on the map. Commuting times with use of public transportation have been taken from https://jizdnirady.idnes.cz/vlakyautobusymhdvse/spojeni/. Starting point of the commute time was chosen as 7 a.m., the application was set to opt for the best time efficiency.

The relationship between the market value of property, commute time, dwelling size, density of population, and building height uses the Alonso-Muth-Mills model. Basic relationships are shown in Figure 1, Figure 2 and Figure 3.

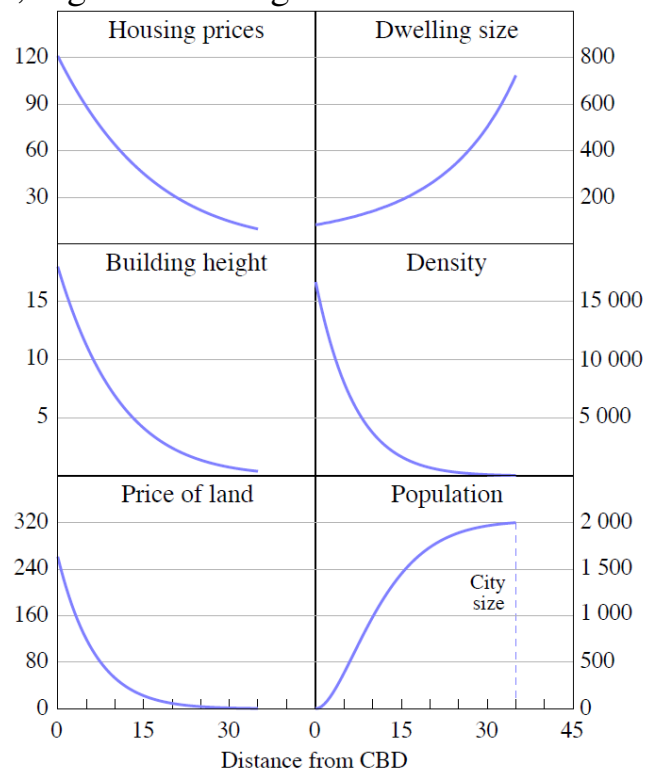

Fig. 1. Unconstrained urban equilibrium [7]

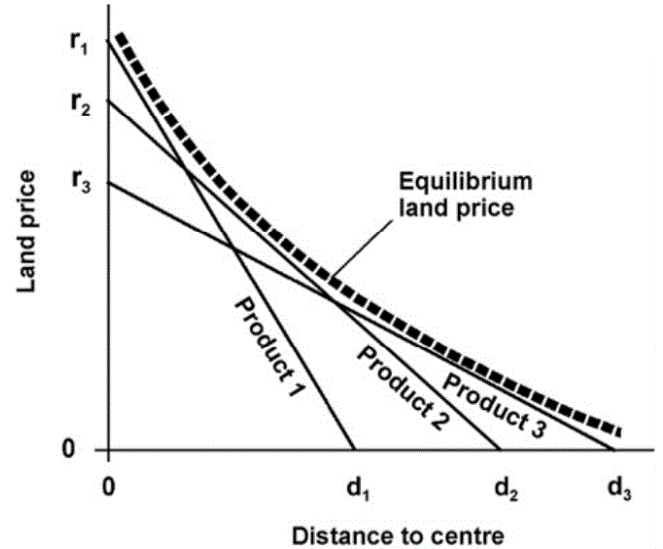

Fig. 2. Bid-rent theory [8]

This paper used only linear regression. Figures 1 and 2 used nonlinear regressions, because it is based on a much larger set of data, than the author of the paper can use. However, the principle and relationship are similar. Figures 1 and 2 represent only a schematic drawing, Figures 4 to 9 are based on specific data determined by own research.

The Alonso-Muth-Mills model is based on the assumption that a city has a fixed population and a given income level living around the central business district (CBD) [9], [10]. Each resident tries to maximize his utility by allocating his income to the consumption of a composite good and land [11]. The model explains some urban landscapes, such as buildings being taller near the CBD, while housing sizes are larger in the suburbs [12]. 


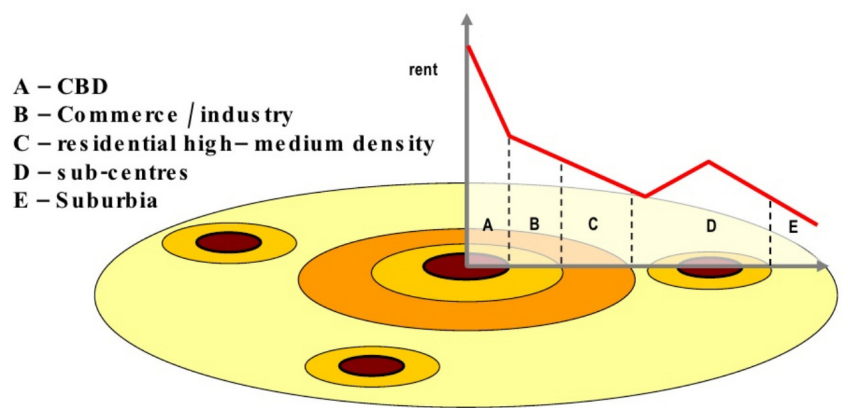

Fig. 3. Variations to bid-rent theory, source: 5 Urban Models, https://www.slideshare.net/, 2009

The relation between the market value of property and commute time can be expressed by the following equation:

$$
r=y-t d,
$$

where $r$ - the rent value (property value, selling price);

$y$ - income of inhabitants in given area;

$t$ - the costs of commuting per unit of distance;

$d$ - the distance between dwelling and CBD.

For the sake of simplification, let us presume within an urban model that all inhabitants of the location have the same income $y$, and that the rent/selling price drops with increasing the distance from the CBD.

It has been established that the relation between the market value of property and commute time can be expressed by means of linear regression. It concerns two-dimensional sample points with one independent variable and one dependent variable. When such line is expressed as an equation, where:

$$
y=b_{1} x+b_{2},
$$

the goal is finding optimal values of coefficients $b_{1}$ and $b_{2}$.

\section{Results and discussion}

Three following figures show relations between the average market value of property for sale for $\mathrm{m}^{2}$ of floor space, its distance from CBD in $\mathrm{km}$, accessibility of CBD using mass transportation in minutes spent in given form of transport and accessibility of CBD using a passenger car expressed in minutes spent in given form of transport.

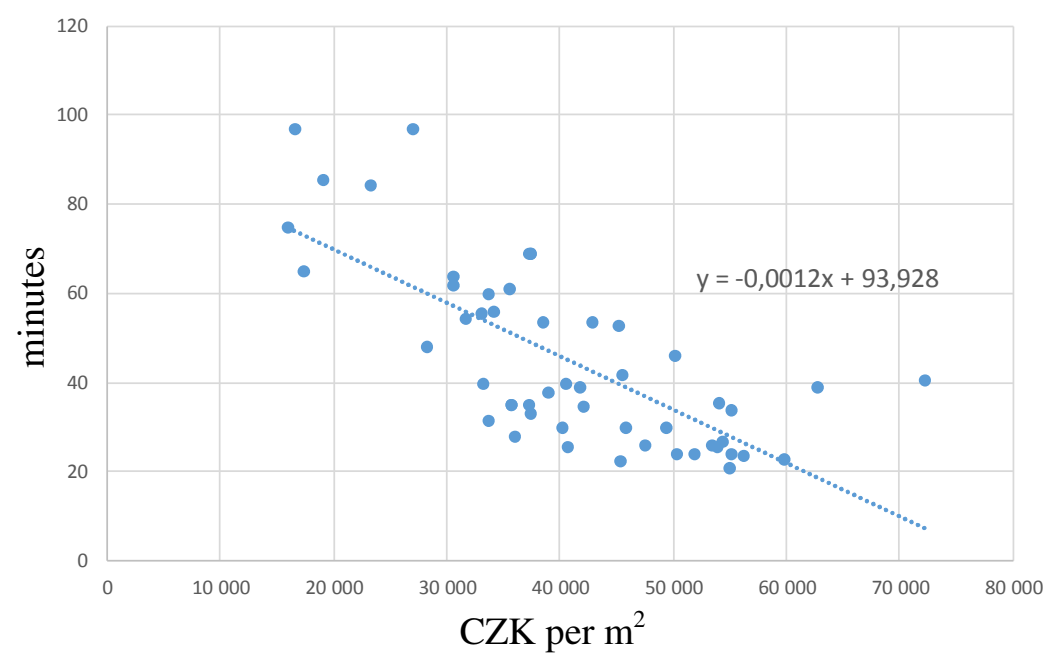

Fig. 4. Relationship between selling price of apartment per $\mathbf{m}^{2}$ and availability of city centre by passenger car (expressed in minutes spent in transport) 


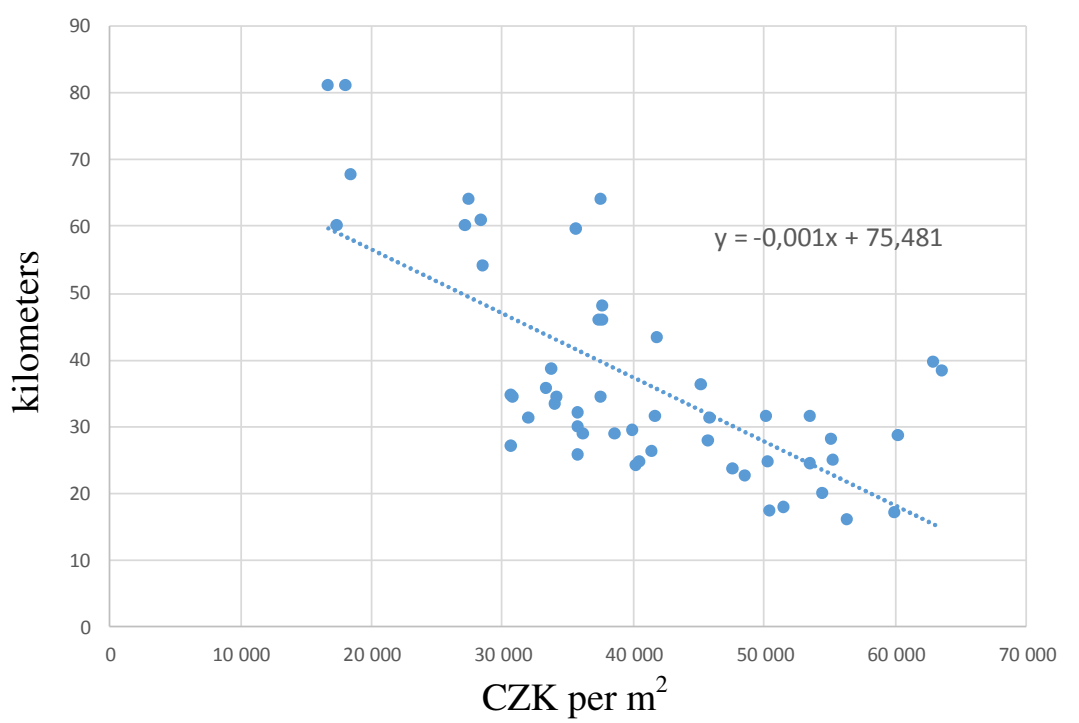

Fig. 5. Relationship between selling price of apartment per $\mathbf{m}^{2}$ and distance of city centre (expressed in kilometres)

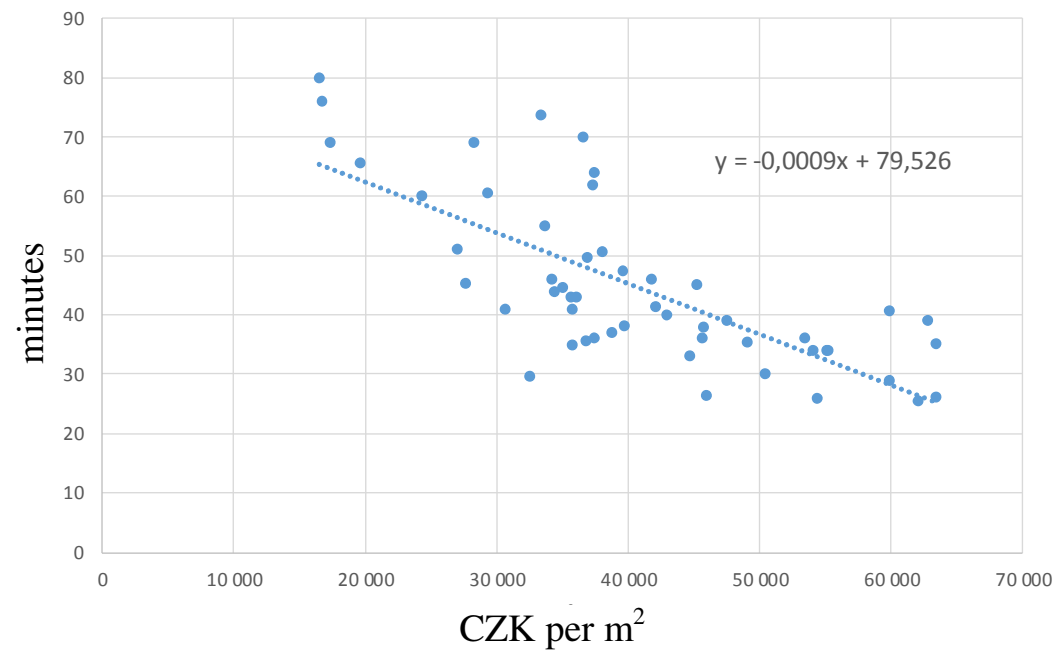

Fig. 6. Relationship between selling price of apartment per $\mathbf{m}^{2}$ and availability of city centre by public transport (expressed in minutes spent in transport)

Three following figures show relations between the average market value of property for rent for $\mathrm{m}^{2}$ of floor space, its distance from CBD in $\mathrm{km}$, accessibility of CBD using mass transportation in minutes spent in given form of transport, accessibility of CBD using a passenger car expressed in minutes spent in given form of transport. It shows that the dependence is lower than in case of property for sale. Such is the reason why Figures 7 and 8 do not carry the line of regression.

It has been established that there is a significant relationship between the market value of property, time of commute necessary to reach CBD and the property's distance from CBD. The following correlation coefficients have been calculated.

- Relationship between the selling price of an apartment per $\mathrm{m}^{2}$ and the availability of the city center by a passenger car - correlation coefficient $=-0.71$.

- Relationship between the selling price of an apartment per $\mathrm{m}^{2}$ and its distance from the city center - correlation coefficient $=-0.68$.

- Relationship between the selling price of an apartment per $\mathrm{m}^{2}$ and the availability of the city center by public transport - correlation coefficient $=-0.75$. 


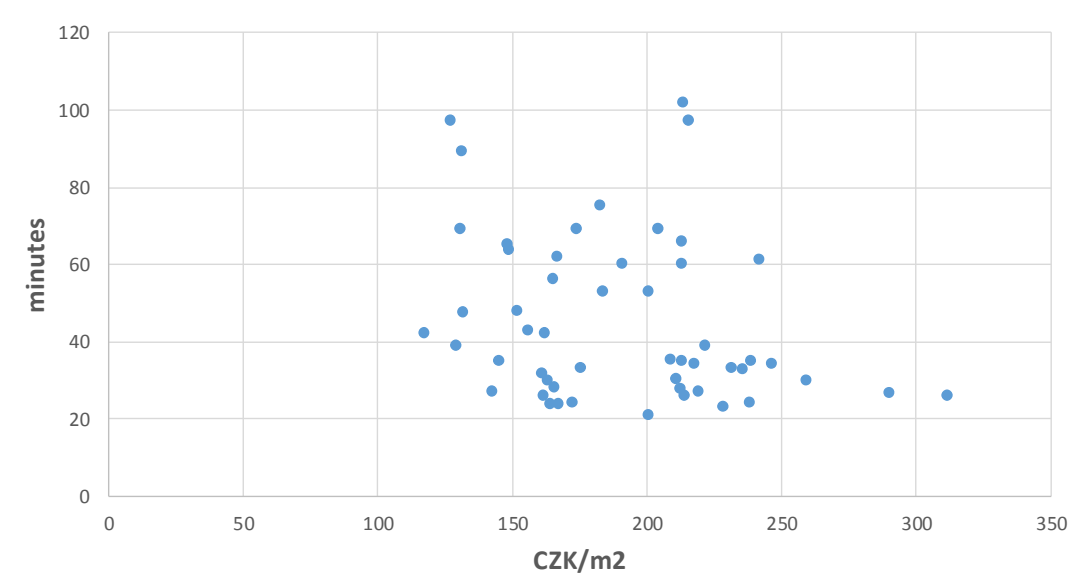

Fig. 7. Relationship between rental price of apartment per $\mathbf{m}^{2}$ and availability of city centre by passenger car

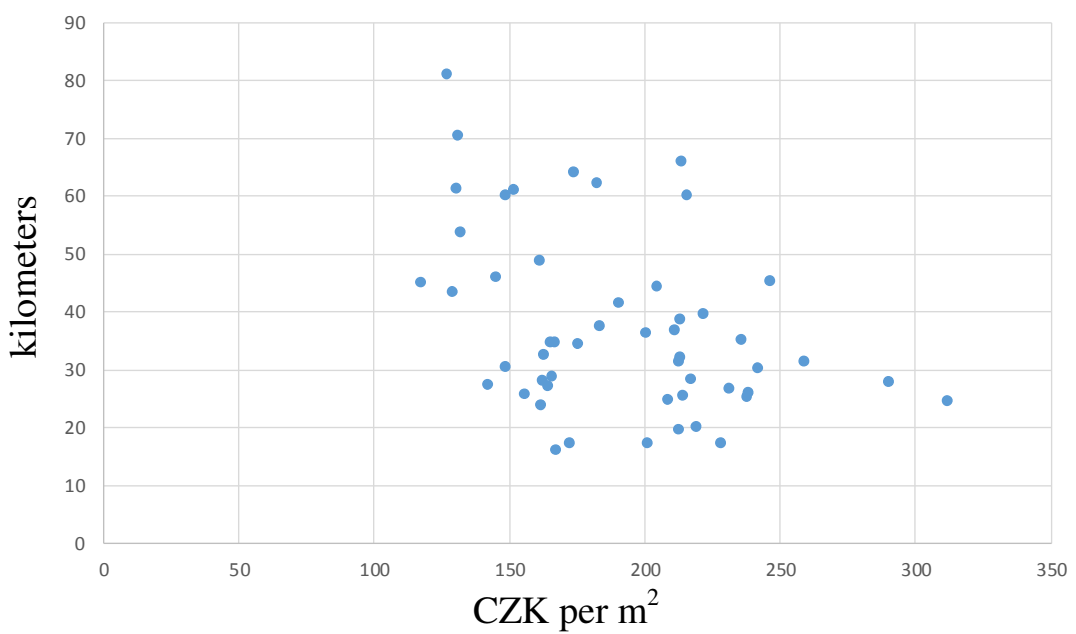

Fig. 8. Relationship between rental price of apartment per $\mathbf{m}^{2}$ and distance of city centre

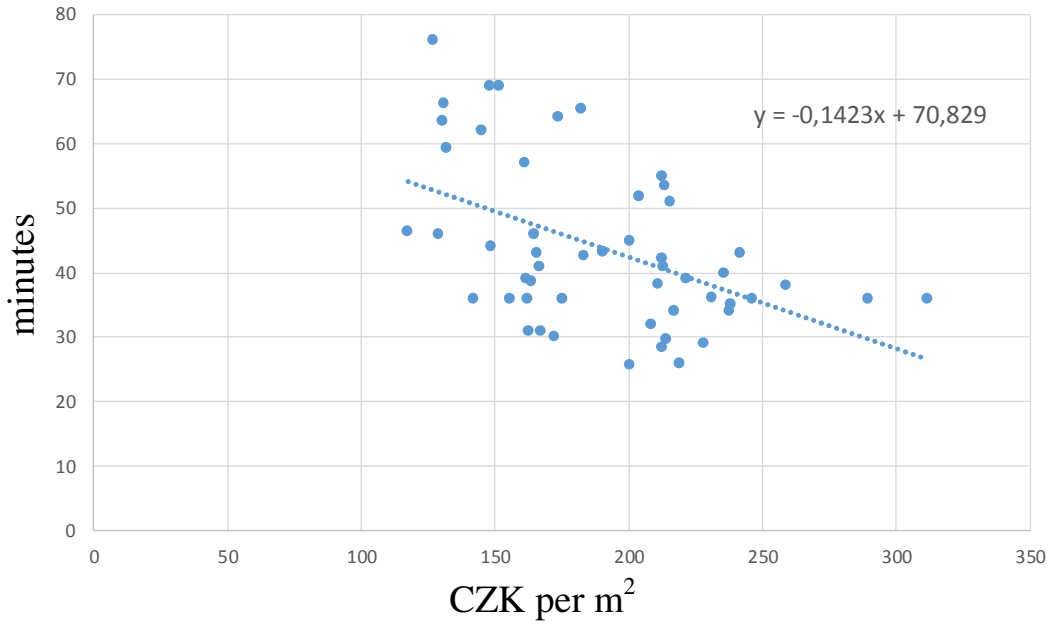

Fig. 9. Relationship between rental price of apartment per $\mathbf{m}^{2}$ and availability of city centre by public transport (expressed in minutes spent in transport)

\section{Conclusions}

Our analysis has found that with every extra minute of commute to CBD, the market value of property drops by about $820 \mathrm{CZK}$ per $\mathrm{m}^{2}$ of floor space. Similarly, with each extra kilometre from 
$\mathrm{CBD}$, the market value of property drops by about $1,150 \mathrm{CZK}$ per $\mathrm{m}^{2}$. A regression analysis is graphically plotted in Figures 4 to 6 and Figure 9. Scatterplots and regression lines were used.

In case of rental property, we have established a lower degree of mutual relationship of variables. The correlation coefficients carry the following values: $-0.31 ;-0.47 ;-0.54$. With rental flats, the highest relationship can be found between the market value and city centre accessibility using public transportation. Accessibility by means of a passenger car or the distance from CBD do not reach such importance in establishing the market value.

This can be attributed to the characteristics of the target groups of buyers. It can be assumed that the purchasing power of the tenants is lower than the purchasing power of the potential property owners. Therefore, these groups attribute different importance to individual price establishing factors.

In the Czech Republic, there has been a significant increase in the price level of sales and rental of housing units in recent years. This is due to the macroeconomic and monetary policy of the Czech National Bank, easy access to mortgage loans for a wide group of buyers, low interest rates and the positive state of the economy in the Czech Republic. However, there has been a change in recent months. There is cooling of the real estate market and the number and volume of mortgages. It can therefore be expected that buyers will look much further at price-forming factors of real estate. This will increase differences in the price level between individual locations. Therefore, an increase in these correlation coefficient values can also be expected.

\section{Acknowledgements}

This work was supported by the Grant Agency of the Czech Technical University in Prague, grant No. SGS17/121/OHK1/2T/11.

\section{References}

[1] Kaderabkova B., Lukavec M. How much does a minute of commuting time cost? An examination of property prices in relation to distance to the city center in Prague, Czech republic [online]. The Civil Engineering Journal. 2017, 0(4), pp. 555-567. ISSN 1805-2576. [online][11.02.2018]. Available at: http://www.civilengineeringjournal.cz/archive/issues/2017/2017_4/4-2017-0044.pdf.

[2] Seo K., Salon D., Kuby M., Golub A. Hedonic modeling of commercial property values: Distance decay from the links and nodes of rail and highway infrastructure. Transportation, 2018, pp. 1-24. 10.1007/s11116-018-9861-z.

[3] Diao M., Leonard D., Sing, T. F. Spatial-difference-in-differences models for impact of new mass rapid transit line on private housing values. Regional Science and Urban Economics, 67, 2017, pp. 64-77. 10.1016/j.regsciurbeco.2017.08.006.

[4] Hromada E. Analysis of the real estate market in the Czech Republic. Business \& IT. 2017, 7(1), pp. 32-37. [online][11.02.2018]. Available at: http://bit.fsv.cvut.cz/issues/01-17/full_0117_05.pdf.

[5] Liu J. G., Zhang X. L., Wu W. P. Application of fuzzy neural network for real estate prediction. In: 3rd International Symposium on Neural Networks, ISNN 2006 - Advances in Neural Networks. Chengdu. China. Volume 3973 LNCS, 2006, pp. 1187-1191.

[6] Jones J., Peeters D., Thomas I. Is cities delineation a pre requisite for urban modelling? The example of land price determinants in Brussels. CyberGeo, 2015.

[7] Kulish M., Richards A. Gillitzer Ch. Urban Structure and Housing Prices: Some Evidence from Australian Cities [online]. Reserve Bank of Australia. 2011. [online][11.02.2018]. Available at: https://www.rba.gov.au/publications/rdp/2011/2011-03/alonso-muth-mills-model.html.

[8] Presentation on theme: "Land Use and Transportation Models G111/211a Draft Notes" (2018). [online][11.02.2018]. Available at: http://slideplayer.com/slide/4949663/.

[9] Anas A., Arnott R., Small K. A. Urban spatial structure. University of Buffalo, Boston College, and the University of California at Irvine. California, USA, 1998, pp. 11-12.

[10] Mills E. An aggregative model of resource allocation in a metropolitan area, American Economic Review 57, 1967, pp. 197-210.

[11] Lai F., Tsai J. Simplified Alonso-Mills-Muth model with a monopoly vendor. Journal of Urban Economics, Volume 63, Issue 2, 2008, pp. 536-543. https://doi.org/10.1016/j.jue.2007.03.007.

[12] Brueckner J. The structure of urban equilibria: A unified treatment of the Mills-Muth model, in: P. Nijkamp (Ed.), Handbook of Regional Economics, vol. 2, North-Holland, 1986, pp. 821-854. 